\title{
Scrotal wall metastasis as the first manifestation of primary gastric adenocarcinoma
}

\author{
ST Leung *, CY Chu, Billy MH Lai, Florence MF Cheung, Jennifer LS Khoo
}

A B S T R A C T

Metastases to the scrotal wall are very rare, and being the initial manifestation of occult primary tumours is even rarer. We report on a patient presenting with painless scrotal swelling, attributed to a solid extra-testicular mass found on ultrasonography. Subsequent investigations and surgical exploration revealed it to be a scrotal wall metastasis from an occult gastric primary. To our knowledge, this is the first report of a scrotal wall metastasis from gastric adenocarcinoma. The ensuing discussion and literature review highlight the diagnostic challenges posed by an extra-testicular scrotal metastasis from an occult primary tumour.

\author{
Hong Kong Med J 2014;20:70-3 \\ DOI: $10.12809 / \mathrm{hkmj} 133879$ \\ ${ }^{1}$ ST Leung *, MB, BS, FRCR \\ ${ }^{1}$ CY Chu, FRCR, FHKAM (Radiology) \\ BMH Lai, MB, BS, FRCR \\ ${ }^{2}$ FMF Cheung, FRCPath, FHKAM (Pathology) \\ 1 JLS Khoo, FRCR, FHKAM (Radiology) \\ 1 Department of Radiology \\ Department of Clinical Pathology \\ Pamela Youde Nethersole Eastern Hospital, Chai Wan, Hong Kong \\ * Corresponding author: baryleung@hotmail.com
}

be a scrotal wall metastasis from an occult gastric adenocarcinoma. To our best knowledge, there has been no previous report of a scrotal wall metastasis from gastric adenocarcinoma.

\section{Case report}

A 66-year-old man, who enjoyed unremarkable past health, presented with a 2 -week history of painless we report on a patient who presented with a solid extra-testicular mass, which was later confirmed to

Metastases from gastric adenocarcinoma to scrotal structures are rare, most being intra-testicular Extra-testicular metastases are even rarer. It is extremely rare for such a metastasis to be the first manifestation of an occult primary tumour. Herein
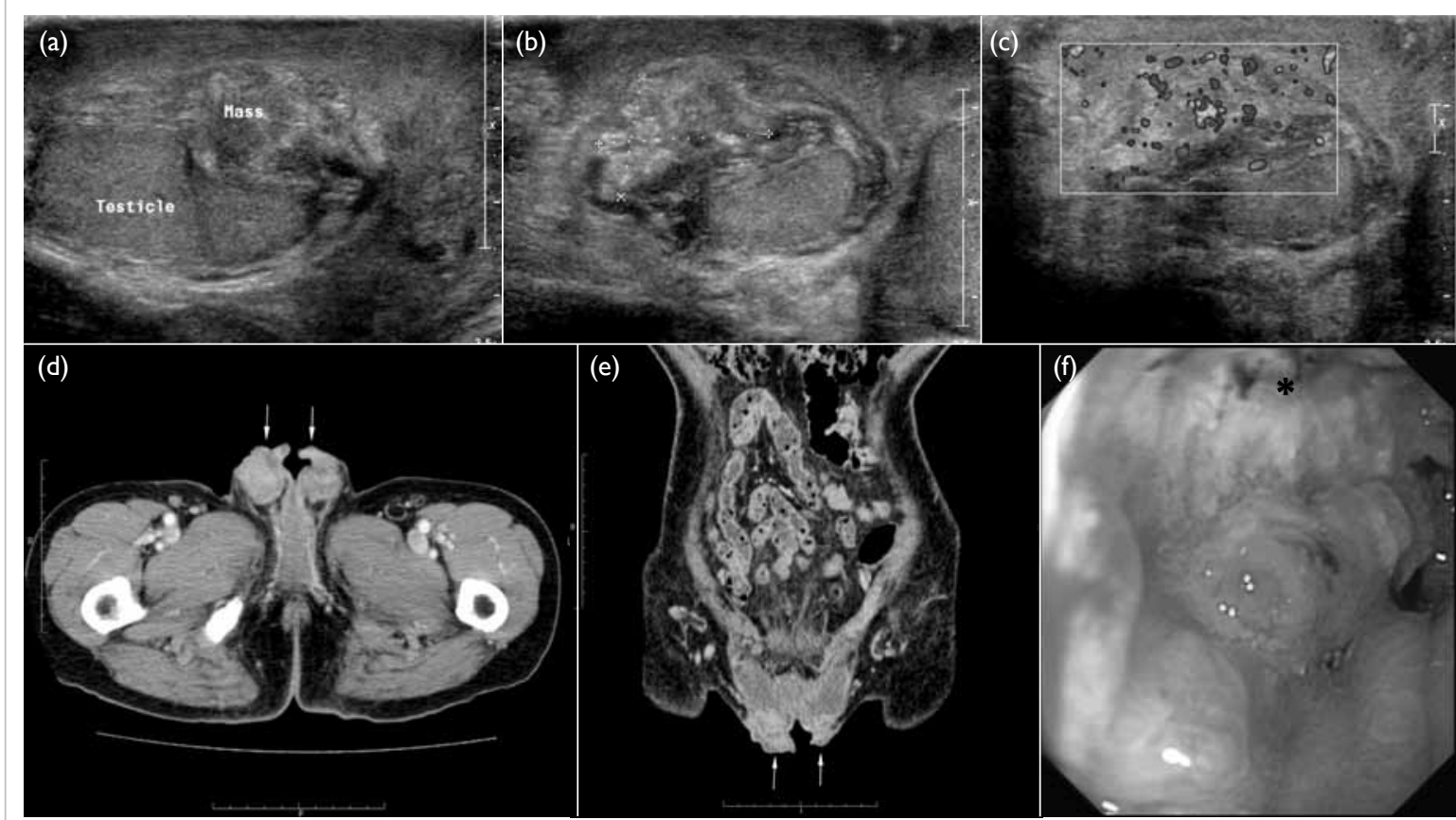

FIG I. (a) Longitudinal and (b) transverse sonography of the right scrotum showing a solid extra-testicular mass separated from the normal-looking right testis. (c) Increased vascularity was evident on Doppler study. (d) Axial and (e) coronal computed tomographic images of the scrotum revealing bilateral scrotal soft-tissue thickening (arrows). (f) The oesophagogastroduodenoscopy reveals an irregular ulcerative tumour $\left(^{*}\right)$ over the lower part of gastric body 
'right testicular' swelling in May 2011. Examination yielded a 4-cm hard, irregular, and non-tender right scrotal mass.

An urgent ultrasound revealed an $18 \mathrm{x}$ $13 \mathrm{x}$ 21-mm solid extra-testicular mass with heterogeneous echogenicity in the right scrotum (Figs 1a-c), which was separate from the normallooking right testis. Equivocal involvement of the right epididymis was noted on the ultrasound at that time. Increased vascularity of the mass lesion was noted on colour Doppler study. A small right hydrocele was also evident.

In view of a possible malignancy, the patient then underwent surgical scrotal exploration, which revealed a markedly thickened scrotal wall. The dartos muscles could not be well delineated and considered a probable sight of invasion by tumour, though the fat plane between the scrotal wall and the tunica was preserved. The testes could be well separated from the thickened scrotal wall.

A full-thickness scrotal wall incisional biopsy revealed diffuse infiltration of the subcutaneous tissue and dartos muscle by aggregates and islands of adenocarcinoma, more heavily on the right side. Evidence of a desmoplastic reaction was noted. The scrotal skin was unremarkable (Figs 2a-b).

Immunological studies showed that the tumour
陰囊壁病變作為原發性胃腺癌轉移

梁肇庭、朱志揚、賴銘曦、張文鳳、邱麗珊

癌轉移至陰囊壁非常罕有, 而作為隱匿性原發腫瘤的初發表現更是罕 見。本文報告一名出現無痛性陰囊腫脹的病人, 在超聲圖上顯示在睪 丸以外有一個灶。隨後的檢測及手術均證實此灶從一個隱匿性胃癌轉 移至陰囊壁。據我們所知, 這是首宗陰囊壁病變作為原發性胃腺癌轉 移的病例報告。本文續討論從隱匿的原發腫瘤轉移至睪丸所帶來的診 斷挑戰，並作文獻回顧。

cells were positive for CK7, carcinoembryonic antigen, p53, and CDX2; focally positive for CK20 and negative for prostate-specific antigen (Figs $2 \mathrm{c}-\mathrm{f})$. These features favoured a tumour of the upper gastro-intestinal or genital origin. Biopsies of the urethra and urinary bladder from the same operation were negative of malignancy.

Subsequent computed tomography (CT) of the abdomen and pelvis to search for any underlying malignancy showed bilateral scrotal soft tissue thickening (Figs 1d-e), and oesophagogastroduodenoscopy revealed a hard, irregular, and circumferential ulcerative tumour over the lower part of body of stomach (Fig 1f).

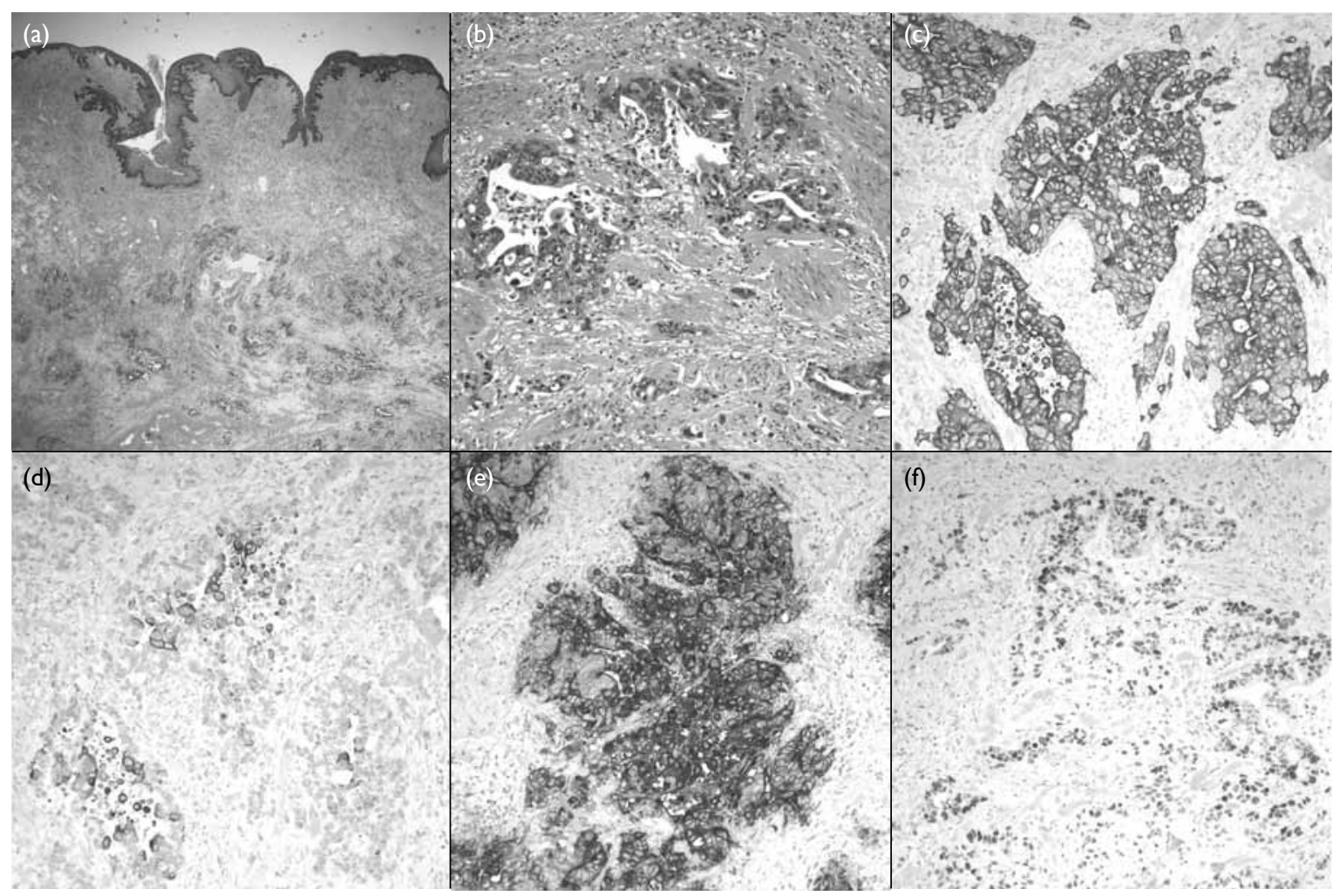

FIG 2. Pathological examination showing that (a) the soft tissue underlying the scrotal skin was infiltrated by adenocarcinoma $(\mathrm{H} \& \mathrm{E}, \times 20)$ and (b) malignant glands lined by pleomorphic cells seen in the dartos muscle (H\&E, $x$ 200). Immunohistochemical studies (x 200) showing (c) tumour cells positive for CK7, but (d) only focally positive for CK20, and (e) strongly positive for carcinoembryonic antigen and $(f)$ partly positive for $\mathrm{p} 53$. The overall features favour a tumour from the upper gastro-intestinal or genital origin 
Biopsy of this ulcerative tumour revealed a poorly differentiated adenocarcinoma.

Palliative chemotherapy with the XELOX regimen (capecitabine plus oxaliplatin) was started. The chemotherapy regimen was subsequently changed to the FOLFOX regimen (folinic acid, fluorouracil, and oxaliplatin) because of progression of the gastric malignancy. He remained otherwise asymptomatic 10 months following the initial presentation, when this report was submitted for publication.

\section{Discussion}

The scrotum is a musculocutaneous sac composed of two compartments, divided by a midline septum. Each compartment contains a testis, epididymis, spermatic cord, and associated fascial coverings. The scrotal wall is composed of pigmented skin, subcutaneous tissue, and the closely related dartos fascia and dartos muscle.

Metastases to scrotal structures are rare. Among these, the testis is the most frequently involved site. Less than $3 \%$ of testicular malignancies are secondaries; the lung, prostate, and gastrointestinal tract are the most common primary sites. ${ }^{2,3}$ Metastases to extra-testicular scrotal structures such as the epididymis, spermatic cord, and scrotal wall are even rarer. Metastases account for 8.1\% of malignancies in the epididymis and spermatic cord, ${ }^{3,4}$ mostly reported as single case reports. ${ }^{3}$

Metastasis to the scrotal wall involving the subcutaneous tissue and dartos muscle with normal scrotal skin (as in our patient) is extremely rare. A previous review could only identify sporadic cases of scrotal wall metastases; the primaries being from malignant melanoma, anal carcinoma, and lung carcinoma. ${ }^{5}$ To our best knowledge, no scrotal wall metastasis from gastric adenocarcinoma has ever been reported in the literature. On the other hand, cutaneous metastases involving the scrotal skin alone are relatively more common. In contrast to scrotal wall metastases which present as a scrotal swelling, scrotal skin metastases present as cutaneous polypoid lesions, ulcers, or papules. ${ }^{6-8}$

Several pathways by which primary tumours metastasise to the scrotal structures have been proposed. They include retrograde venous embolism, retrograde lymphatic extension, arterial embolism, direct invasion along the testicular cord, and transperitoneal seeding through a congenital hydrocele. ${ }^{9}$ Although the exact pathway of the metastasis in our patient is not clear, absence of intra-abdominal, pelvic lymphadenopathy, and testicular cord thickening all favour embolism or transperitoneal seeding as the route.

Clinically, a scrotal wall metastasis usually presents as a painless scrotal swelling with normal overlying skin, with a firm-to-hard mass being evident on physical examination. Ultrasonography usually reveals a solid extra-testicular mass, that is mostly hypoechoic but can have variable echogenicity. ${ }^{2}$ Previously described sonographic features of a scrotal wall metastasis from a lung primary also entailed increased peripheral vascularity and poor delineation with the epididymis, ${ }^{2}$ in which the features were also observed in our patient.

Ultrasonography is usually the first imaging modality for evaluating patients presenting with scrotal swelling. Its high spatial resolution provides nearly $100 \%$ sensitivity in identifying a scrotal mass and a 98 to $100 \%$ sensitivity in differentiating intra-testicular versus extra-testicular lesions. ${ }^{1}$ The two most important factors to consider during evaluation of a scrotal mass are whether it is intra- or extra-testicular in location, and whether it is cystic or solid in nature. ${ }^{1}$ This is because more than 95\% intra-testicular masses are malignant while most that are extra-testicular are benign. ${ }^{10}$

Most extra-testicular masses are cystic and almost all are benign. ${ }^{1}$ Solid extra-testicular masses are uncommon and $97 \%$ of them are also benign. ${ }^{1,11}$ Among these solid extra-testicular masses, lipoma and adenomatoid tumours are most frequently encountered, and account for about $45 \%$ and $33 \%$ of all extra-testicular masses, respectively. ${ }^{11}$

Malignancies account for the remaining 3\% of extra-testicular masses. It was estimated that $8.1 \%$ of malignancies in the epididymis and spermatic cord are due to metastases., ${ }^{3,4}$ Rhabdomyosarcoma is the most common primary malignant tumour, accounting for $40 \%$ of all malignant extra-testicular tumours and are most common in infants and children. ${ }^{11}$ In adults, examples of primary malignant tumours include leiomyosarcoma, liposarcoma, fibrosarcoma, malignant fibrous histiocytoma, and primary adenocarcinoma of epididymis. ${ }^{5}$

Secondary extra-testicular malignant tumours usually occur against a background of known advanced malignancy. Common primary sites include prostate, kidney, gastro-intestinal tract, and pancreas. ${ }^{11}$ Epididymis and spermatic cord are the usual sites of involvement, while scrotal wall metastases are extremely rare. Only sporadic case reports can be identified in the literature for metastases to the scrotal wall (from melanoma, anal carcinoma, and lung carcinoma). ${ }^{2,12}$

Lesion diameter, volume, and presence of vascularity on Doppler ultrasonography assist differentiation of malignant from benign lesions. ${ }^{13}$ Multifocal lesions and heterogeneity have also been suggested as supporting metastatic disease. ${ }^{14,15}$ However, in most instances, considerable overlap in sonographic appearances of many solid extratesticular masses preclude a specific diagnosis. ${ }^{1}$

Magnetic resonance imaging (MRI) is useful in characterising certain extra-testicular lesions such 
as lipoma, haematoma, and fibrous pseudotumour. Enhancement patterns in gadolinium-enhanced MRIs are also useful in differentiating malignant from benign lesions. In such cases, MRI findings may obviate the need for surgery or change the surgical approach. ${ }^{14}$

In patients without a known history of malignancy such as ours, diagnosis of an extratesticular metastasis on the initial ultrasound is difficult. The sonographic differential diagnosis includes other extra-testicular benign and malignant tumours. Clinical correlation is essential to enable better differentiation of malignant from benign lesions. The clinical finding of a hard scrotal mass in our patient raised concerns of malignancy, and hence surgical exploration was undertaken. The final diagnosis still depends on biopsy and pathological study. In our patient, histology and immunological studies of the scrotal wall biopsy hinted at the final diagnosis of occult gastric adenocarcinoma. Although positron emission tomography-CT may be useful for seeking an occult primary malignancy, it is not commonly used as a first-line imaging modality in patients presenting with a scrotal wall lesion. However, it could be offered to search for an underlying primary when histology shows adenocarcinoma but immunological study results are pending.

\section{Conclusion}

Extra-testicular metastases are rare and have nonspecific sonographic features, which always pose difficulties in diagnosis, particularly in patients without a known primary malignancy. We hereby report the first case of a gastric adenocarcinoma presenting as scrotal wall metastasis. This case also demonstrates the importance of radiological, clinical, and pathological correlations in making the final diagnosis.

\section{References}

1. Woodward PJ, Schwab CM, Sesterhenn IA. From the archives of the AFIP: extratesticular scrotal masses: radiologic-pathologic correlation. Radiographics 2003; 23:215-40.

2. Dogra V, Saad W, Rubens DJ. Sonographic appearance of scrotal wall metastases from lung adenocarcinoma. AJR Am J Roentgenol 2002;179:1647-8.

3. Dutt N, Bates AW, Baithun SI. Secondary neoplasms of the male genital tract with different patterns of involvement in adults and children. Histopathology 2000;37:323-31.

4. Algaba F, Santaularia JM, Villavicencio H. Metastatic tumor of the epididymis and spermatic cord. Eur Urol 1983;9:56-

5. Dogra VS, Gottlieb GH, Oka M, Rubens DJ. Sonography of the scrotum. Radiology 2003;227:18-36.

6. Aridogan IA, Satar N, Doran E, Tansug MZ. Scrotal skin metastases of renal cell carcinoma: a case report. Acta Chir Belg 2004;104:599-600.

7. McWeeney DM, Martin ST, Ryan RS, Tobbia IN, Donnellan PP, Barry KM. Scrotal metastases from colorectal carcinoma: a case report. Cases J 2009;2:111.

8. Wang SQ, Mecca PS, Myskowski PL, Slovin SF. Scrotal and penile papules and plaques as the initial manifestation of a cutaneous metastasis of adenocarcinoma of the prostate: case report and review of the literature. J Cutan Pathol 2008;35:681-4.

9. Hanash KA, Carney JA, Kelalis PP. Metastatic tumors to the testicles: routes of metastasis. J Urol 1969;102:465-8.

10. Moghe PK, Brady AP. Ultrasound of testicular epidermoid cysts. Br J Radiol 1999;72:942-5.

11. Akbar SA, Sayyed TA, Jafri SZ, Hasteh F, Neill JS. Multimodality imaging of paratesticular neoplasms and their rare mimics. Radiographics 2003;23:1461-76.

12. Ferguson MA, White BA, Johnson DE, Carrington PR, Schaefer RF. Carcinoma en cuirasse of the scrotum: an unusual presentation of lung carcinoma metastatic to the scrotum. J Urol 1998;160(6 Pt 1):2154-5.

13. Alleman WG, Gorman B, King BF, Larson DR, Cheville JC, Nehra A. Benign and malignant epididymal masses evaluated with scrotal sonography: clinical and pathologic review of 85 patients. J Ultrasound Med 2008;27:1195202.

14. Cassidy FH, Ishioka KM, McMahon CJ, et al. MR imaging of scrotal tumors and pseudotumors. Radiographics 2010;30:665-83.

15. Souza FF, Di Salvo D. Sonographic features of a metastatic extratesticular gastrointestinal stromal tumor. J Ultrasound Med 2008;27:1639-42. 